\title{
The importance of information logistics for successful implementation of EU research projects
}

\author{
Maja Mikšić ${ }^{1}$, Ljerka Luić ${ }^{2}$ \\ ${ }^{1}$ Karlovac University of Applied Sciences, Trg J.J. Strossmayera 9, Karlovac, Croatia, \\ maja.miksic@vuka.hr \\ ${ }^{2}$ Karlovac University of Applied Sciences, Trg J.J. Strossmayera 9, Karlovac, Croatia, \\ ljerka.luic@vuka.hr, ljerka.luic@b4b.hr
}

Keywords

Information logistics, research project, EU funded, ICT, INTREPID.

\section{ABSTRACT}

In research projects, information logistics is becoming an increasingly important link between all project phases and elements and their stakeholders, the implementation of which is unthinkable without using ICT. The answers to the question 'How important?' are elaborated in the paper, which describes the development of information logistics used in the implementation of the INTREPID project funded by the EU fund IPA intended for investing in knowledge and innovation. The importance of information logistics is supported by information on the complexity of storing documents and data, the extensiveness and complexity of reporting and communication between project stakeholders is analyzed through all project phases: from project idea development and implementation of project activities to project completion. The extensiveness and complexity of reporting defined by the EU rules, procedures and forms additionally indicate the importance of information logistics in successful monitoring and management of research projects. All this leads to the conclusion that information logistics is irreplaceable in all phases of the external and internal project cycle, the efficiency of which would be largely supported by an integrated information system developed and applicable on the level of all EU research projects.

\section{INTRODUCTION}

The importance of information logistics is irreplaceable in all phases of the external and internal project cycle. Various project management software and applications are available on the market, but most of them are commercial and the licensing arrangements make them unaffordable to most higher education institutions. An additional issue regarding their use in the implementation of EU funded projects arises from the fact that they are not in line with the required EU forms in the reporting component. Based on the conducted research $[\mathrm{MM}]$, it is possible to establish with a degree of certainty that there is no single software/applicative solution that could at the same time be used for implementing EU projects in all program components. Despite using standardized application forms and reporting forms, activity management and budget management are significantly different with respect to the project purpose, subject, objective and goal. After signing the EU grant agreement, it would be very useful to have software or just a project-compatible module available for efficient implementation monitoring of the agreement, which is not the case in practice. Considering the time and financial limitations in project implementation, beneficiaries of EU funds use normal software, especially software containing predefined forms for the preparation and submission of tender documents and reporting forms such as MS Office programs using the available ICT infrastructure. The INTREPID project is short for INnovation, Technology Transfer and $\underline{R}$ Esearch Provision Infrastructure Development, which fully describes and summarizes the purpose and goal of the project. The project's name originates from the time when the tender documents were being prepared in 2009, at which point the details regarding the difficulties in its implementation, in case it had been positively evaluated and selected for implementation, were not known. Despite this, the application was bravely and intrepidly submitted, the project was selected and contracted, and successfully implemented in 2012 at the Karlovac University of Applied Sciences, Croatia. 


\section{MATERIALS AND METHODS}

\subsection{Definitions}

Information logistics is a set of logistic activities that ensure systematic and efficient collection of primary and secondary data and enhance their processing, use and exchange with other active stakeholders, encouraging institutions to efficiently use the great potential of modern ICT.

EU funded research projects are the projects that provide critical mass of research resources and contribute to enhancing European Union's competitiveness, or satisfy the needs of the European society. They inevitably include a research component, but they may also include a technological or demonstrative component, or a training element.

\subsection{Subject and Objective of the Paper}

Considering the challenges of the 'fourth era' that higher education is also exposed to, and the research results of which are largely dependent upon the potential of their information systems and the degree of their integration, the subject of the paper is analyzed on a three-dimensional basis: it includes information, IT and logistic aspects and is seen from the perspective of its active stakeholder.

Regarding the whole issue of research, the overall objective of the paper is focused on probing into the importance of information logistics in the context of successful management of EU research projects in higher education, and to gain insight into whether and to which extent the potentials of new information technologies and solutions are incorporated in their implementation.

Its indirect aim is to demonstrate the dependence of successful implementation of EU research projects on ICT-based information logistics on practical examples, indicate their importance, and encourage the present and prospective EU project stakeholders to think about the issue raised, their share in its resolution and better understanding of difficulties encountered by them during operational project implementation.

\subsection{Hypotheses}

Rudimentary hypotheses in the form of unstructured claims concerning the solutions for the identified problems existed at the time of their identification, after a careful examination of the administrative requirements set by the EU for research projects, only to obtain their forms of structured claims, the authenticity of which needs to be confirmed or refuted, through the process of defining the subject and objectives of the paper and during its creation.

$\mathrm{H}_{1}$ : There is no single applicative solution on the market to support the implementation of EU projects, the functionalities of which are in full compliance with the EU requirements for organizational, operating, reporting and controlling project activities.

$\mathrm{H}_{2}$ : Developing an applicative solution internally within the defined project period was not possible.

$\mathrm{H}_{3}$ : The implementation of project activities within the defined period would not have been possible without information logistics.

\subsection{Data Sources and Collection Methods}

The used sources of information may be classified as bibliographic, electronic and research. The primary sources of bibliographic information were books, scientific and professional journals and almanacs, while the secondary ones were manuals, dictionaries, legal regulations and laws.

The internet was the most commonly used source in searching electronic sources of information on various websites, reading electronic journals and database mining. Information sources stored on CDs were a somewhat less represented, but no less important electronic source.

Specific information and data presented in this paper were primarily collected from databases within the INTERPID project, websites of project stakeholders, and other websites relevant to the implementation of EU projects. All information about the project was collected solely by using computers. 


\section{RESULTS}

This section summarizes, in the form of integrated results, the data and information obtained by implementing the subject of research analyzed within the boundaries of the INTERPID project and described in five dedicated units: Project Cycle, Communication Aspects, Application Support, Archiving and Reporting, and Auditing.

\subsection{Project Cycle}

From the viewpoint of a beneficiary of a grant for a EU funded research project, the project cycle can be seen as an external and an internal cycle. Beneficiary's external cycle begins as of the date the request for proposals and tender documents are published. This is followed by the collection of the required application forms, evaluation, execution of contract, implementation, and auditing of all project activities in the end. The internal cycle begins by defining the needs of the educational institution for infrastructure, training and equipment. It is also necessary to develop a rough project concept, which may be proposed by a team or individuals possessing relevant knowledge in particular scientific or educational areas. After the concept is developed, it is necessary to intensively monitor tender announcements and publications. After the request for proposals and tender documents are published, an application form is completed, supplemented with annexes and required supporting documentation, and sent to the implementing agency.

This is followed by a lengthy period of uncertainty and waiting for the evaluation results, which normally takes 8-12 months. After receiving the notice of positive evaluation of the project, additional documents are provided as requested by the evaluator, a project account is opened, and the contract is signed. As of the day following the contract execution date, the implementation period begins, during which quarterly reports, an interim report and a final report are submitted.

\subsection{Communication Aspects}

Transferring large amounts of information and communication between the project manager and project team, among project members and with all other project stakeholders must be quick, accurate, confidential and secure. E-mail played an indispensable role in the transfer of all types of information, documents and data. Approximately 550 e-mails were sent to CFCA $^{1}$, MOSES $^{2}$ and auditors alone. The total number of received and sent e-mails relating to the project from the time of completion of the application form in June 2009 until the time this paper was written is estimated at no less than 6000 to 7000 .

\subsection{Application Support}

The contracting/implementing authorities use a locally developed project management solution called MIS as their operating program, but its functionalities are insufficient for the implementation of all management functions, Word and Excel are insufficient for project monitoring purposes, while SAP is insufficient for payments. The controlling authority ARPA ${ }^{3}$ uses software developed according to needs and requirements in cooperation with IT auditors and based on SharePoint Foundation 2010 technology. Data stored in the application may be accessed by an unlimited number of auditors from any location. The application includes audits of all components (departments), regardless of whether they are system audits, operational audits or follow-up on previous audits, and regardless of whether such audits addressed service agreements, supply agreements, work agreements or grant agreements including secondary procurements. In addition to this software, IDEA software is used for selection of samples and data analysis. Independent auditors use Excel, Word and Access Microsoft Office applications, while Amadeus software is used to check transfer pricing (data, organizations, related parties). In addition, they use various web services and databases such as court registries and registries of associations and foundations. To verify data accuracy and analytically review trends in financial statements in comparative periods, they mostly use Word and Excel, and they also use PDF to verify the originality of a document.

\footnotetext{
${ }^{1}$ Central Finance and Contracting Agency

${ }^{2}$ Ministry of Science, Education and Sport

${ }^{3}$ Agency for the Audit of European Union Programmes Implementation System
} 


\subsection{Data Archiving}

Contracting procedures for performance of works, services, and in particular for supply of equipment, must be conducted in accordance with the provisions of PRAG ${ }^{4}$. Considering how stringent these procedures are, a large number of activities and the necessary speed of implementation, but also a large amount of inputs and outputs, the data should be systematically archived and processed, and each step and decision should be justified. All data needs to be archived in electronic and printed formats and be available for auditing purposes for 7 years following the final project approval date. The administrative electronic project folder, including implementation monitoring of most activities such as procurement and contracting of equipment and services, progress reports and correspondence, contains 36,008 documents divided into 5,125 subfolders of $44.6 \mathrm{~GB}$. The printed documentation is archived in only 30 folders. One portion of the documentation comprises internal data and ancillary statements, while another comprises documents and data being an integral part of the required reports and subject to audits.

Please note that the EU does not prescribe how documentation should be archived - this is up to each project owner. It only prescribes the forms and information to be provided in reports. How to systematize and archive such an enormous amount of data is up to the logic used by the operators.

\subsection{Reports}

The project owner is required to prepare financial statements and narrative reports so that the contracting authority could monitor and control the spending of EU funds on the basis of the required content and format for such reports in Word and Excel. Report templates are unified forms in English, applicable to all types of EU projects, regardless of the RFP, component and country concerned.

\subsection{Audits}

Audits are inevitable steps in the implementation of EU funded projects. Each project is subject to reports to be prepared by independent auditing firms, while the relevant expenses are financed from the allocated project funds. An auditing company from Zagreb audited this project. The auditors audited printed documentation archived in folders and compared it against electronic documentation. The Interim Report and the Final Report were recorded onto memory sticks. Each auditor was responsible for one budget head. Data on memory sticks was recorded onto portable computers where all items where checked for content and financially. Additional explanations were requested for a large amount of data, which were sent by e-mail or JUMBO mail.

In addition to such independent auditing, the project is subject to an audit conducted by CFCA as the contracting authority. In this case, the Contracting Authority reviewed the reports provided in electronic format and also requested explanations by e-mail. Eventually, when everything was settled electronically, representatives of CFCA conducted a random visual audit of individual items. The last audit is the ARPA audit at the project owner and the implementing authority, which audits the preceding two audits. Like the other two audits, this audit also transferred data using external memory units from one computer to another, and requested additional explanations by e-mail.

Information technology was used for auditing purposes as well. The logistics provided by Excel, Word, e-mail and portable memory units once again significantly simplified and accelerated the procedures for reviewing reports and the entire project documentation, as well as the preparation of audit reports. The audits were presented in the form of Gantt charts for clearer indication of statuses, but also to monitor the fulfillment of the respective audit plans presented in three phases: planning, fieldwork and reporting, and degree of completion of each one of them, including the relevant documents. Department's active tasks, audits pending approval and documents completed and pending director's, department manager's or audit manager's approval are presented for each component.

All this indicates the necessity of using application support in audit management, both in terms of checking the status of each audit and in terms of statistical findings as a whole.

\footnotetext{
${ }^{4}$ Practical Guide to Contract Procedures for EU External Actions
} 


\section{DISCUSSION}

Information logistics is irreplaceable in all phases of external and internal project cycles in EU research projects. Project management software is available on the market, however, according to the available information, no single controlling software has been developed that could be used in project implementation both for the operational part and for audits conducted by contracting authorities and auditors. Despite the use of standardized application and reporting forms, projects are very different and reporting forms, the purpose, subject, objective and goal of each project are quite different from other projects. This is why their activity and budget management is different, so a special module would have to be developed for each project. Information/logistic support in the management of EU projects is presently based on generally available software, most commonly MS Office, which is installed in every computer, while organizing activities and storing data in electronic format is left to the individual organizational abilities of the project owner.

\subsection{Key Knowledge Obtained}

A descriptive analysis of the volume of project archive in electronic format compared to printed (traditional) format leads to the conclusion that it is impossible to deliver the required reports within the time limits defined for the project without logistic support provided by ICT as compared to traditional technology's logistic support. Unified forms are prescribed for project idea preparation and application, which facilitate and systematically present information necessary for evaluation. Analogously to such unification, experience indicates that there is a need for unified implementation applications that would ensure a permanent updated presentation of the project status and information both to beneficiaries and contracting authorities and auditors. In addition to these facts, the need to have functional and transparent project activity and budget management in place should not be ignored either. "A unified information system would definitely help and provide additional assurance that financial statements provide a true and fair view in all material aspects, especially with respect to the standardization of report forms and data retrieval and using. If such software were programmed adequately and in accordance with the approved activities and budget, it would reduce the time of and simplify certain auditing procedures." 5

The hypotheses set in section 3.3 of this paper were observed and investigated from the perspective of INTREPID project stakeholders, based on information collected on four implementation levels of the project and viewed from the position of the implementation/auditing authorities. Using scientific methods of analysis, synthesis and logical reasoning, the collected information was processed and descriptive results are provided below.

The fundamental baseline hypothesis $\mathrm{H}_{1}$ was confirmed - there is no single applicative solution to support the implementation of EU projects, whose functionalities are in full compliance with EU requirements for organizational, operating, reporting and controlling project activities. Subhypothesis $\mathrm{H}_{2}$ relating to the statement that it would be impossible to develop software internally within the defined project period was not fully confirmed or refuted because no applicative software was developed internally during the project, so it is impossible to conclude whether this is actually possible or not. Sub-hypothesis $\mathrm{H}_{3}$, claiming that project activities could not be implemented within the defined period without using information logistics was confirmed with regard to the times we live and work in, when it is unthinkable to undertake any professional activity without using modern ICT, however, a full confirmation would require implementing a project without ICT-based information logistics within the defined time limits to see whether such project implementation is really possible.

\subsection{Further Research}

Further research of the impact of information logistics on the efficiency of implementation of EU funded research projects, for the purpose of evaluating their expected results and the success in the domain of applying research and innovation and training to the transfer of new technologies in teaching practices, should be conducted in several directions.

${ }^{5}$ Lučić, M. (Director): ANTARES, Accredited Auditors of EU Funded Projects, February 7, 2013 
The first direction should aim to identify as accurately as possible more than a few interactions between stakeholders in an integrated project management information system that would include all institutions across the entire vertical operating implementation hierarchy for the purpose of collecting information representing the main obstacles to better utilization of available EU funds for research purposes. The second direction should focus on collecting a maximum sample of higher education institutions where research could be conducted to define algorithms and procedures for the purpose of detecting independent input variable that would allow a more precise description of changes within each project constituent and their mutual interactions.

To put it shortly, further deep research needs to be conducted ongitudinally on a maximum international sample, while objectives should focus on finding a new measuring instrument that would ultimately have the characteristics of a simulation model and enable determining the degree of IT maturity for each prospective EU research project owner and detecting variable necessary for the development of a unified information logistics model appropriate for such projects.

\section{CONCLUSION}

An integrated information system based on a modular applicative solution with empirically defined procedures scientifically detected in the course of further research would reduce errors in project phases, prevent multiple entry of the same data in different places, and thus reduce the human factor impact on the validity of reports, contribute to better utilization of allocated EU funds, and prevent spending funds beyond the scope of allowed activities. However, such a complex software solution is impossible to develop and test within the period defined for project implementation, so its conceptualization, testing and implementation should be viewed internationally, irrespective of a specific project.

The main conclusion of this paper, articulated through the new premise that the success of EU research projects largely depends on the use of information logistics, the degree of which is in direct correlation with the integration degree of an information system intended for scientific and research purposes, certinaly requires further research.

\section{ACKNOWLEDGEMENT}

The publication of this paper was supported by the Karlovac University of Applied Sciences, to which the authors of this article are grateful for its substantial support.

\section{REFERENCES}

Achterberg, J.S., Gerrit, A. and Heng, M.S.H. (1991). Information systems research in the postmodern period. North Holland: Elsevier Science Publishers BV.

Boaden, R., Lockett, G. (1991). Information technology, information systems and information management: definition and development, European Journal of Information Systems, 1, 23-32.

Dhillon, J.K. (2001). Challenges and strategies for improving the quality of information in a university setting: a case study, Total Quality Management, 12(2), 167-177.

Drucker, P.F. (2002). Managing in the next society. Oxford: Butterworth-Heinemann.

INTREPID website (2013). Innovation, technology transfer and research provision Infrastructure development in Karlovac. Retrieved January 13, 2013, from: http://cmk.vuka.hr/en/intrepid.

Luić, Lj. (2009). Information systems - business, logistic and healthcare information systems. Karlovac, Croatia: Karlovac University of Applied Sciences.

Mikšić, M. (2013). Information support the implementation of EU project: a diploma thesis. Karlovac, Croatia: Karlovac University of Applied Sciences.

SIIF website (2013). Science and Innovation Investment Fund. Retrieved February 3, 2013, from: http://www.siif-croatia.com/en/novosti/potpisani-ugovori-u-sklopu-eu-programa-fond-za-ulaganjeu-znanost-i-inovacije/146.

Zelenika, R., Pupovac, D. (2001). Contemporary consideration of main phenomena of logistic system. Economic Review, 52 (3-4), 354-378. 


\section{AUTHORS' BIOGRAPHIES}

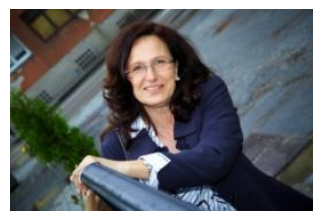

Maja Mikšić, MBA, has over 18 years experience in trade, services and industry. Currently she is employed with the Karlovac University of Applied Sciences, Karlovac, Croatia. The main area of work is application and implementation of the EU funded projects. For the last 4 years she has been involved in $3 \mathrm{EU}$ projects, successfully implemented in Karlovac. In this period she also prepared applications for 5 projects, 1 is currently in evaluation stage. Personal contribution to successful implementation of the projects and very high percentage of achieved goals was in development and organization of project data bases and procedures based on extensive use of ICT technology that can also be applied to other EU projects in general.

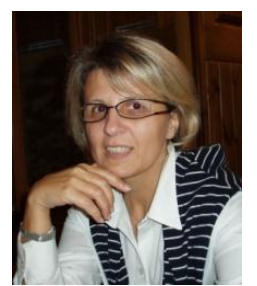

Ljerka Luić has multidisciplinary education (technical: BSC in mechanical engineering, pedagogical: BSC polytechnic teacher; information-communicative: MSC and PhD in information-communication science), and multidisciplinary professional experience (programmer, system engineer, training and human resources director, business development director), based on her work in a scientific institute (Jugoturbina Institute), international corporation (Asea Brown Boveri, SAP), consulting a company (B4B), as well as scientific and teaching experience (University of Zagreb). She is currently a researcher in two scientific projects: Optimizing and Risk Management in Information Systems and Prospects of Application of Management Accounting in Public Sector. Along with scientific work, she is actively lecturing at the Karlovac University of Applied Sciences and is an invited lecturer at the PhD study program at the University of Zagreb, Faculty of Medicine and Faculty of Humanities and Social Sciences. She was mentor to 51 graduate theses, she co-authored 8 scientific papers with graduates (Maja is one of them). She was awarded by Croatian Information Science Association for her contribution to the development and popularization of IT profession. 